\title{
Morphological and behavioral adaptations in Bolitoglossa colonnea (Caudata, Plethodontidae) in relation to habitat use and daily activity cycle
}

\author{
Twan A. A. M. Leenders ${ }^{1}$ and Gregory J. Watkins-Colwell ${ }^{2}$ \\ Division of Vertebrate Zoology, Yale Peabody Museum of Natural History, 170 Whitney Avenue, P. O. Box 208118, \\ New Haven Connecticut 06520-8118, USA. E-mails: twanleenders@ scinax.com, gregory.watkins-colwell@yale.edu.
}

Keywords: Caudata, Plethodontidae, Bolitoglossa colonnea, daily activity cycle, antipredator behavior, color change, skin texture change.

Bolitoglossa colonnea is a member of the Bolitoglossa striatula group (sensu Wake and Lynch 1976) that inhabits low to intermediate elevations on the Caribbean slope of Costa Rica and Panama, and the Golfo Dulce area in southwestern Costa Rica and extreme western Panama. Due to their secretive habits and the low density in which these tropical salamanders generally occur, observations are rare and their natural history remains poorly known. Here we present data from field observations and a behavioral experiment that extend our understanding of the biology of this tropical salamander.

Both Dunn (1926) and Taylor (1952) reported observing specimens of $B$. colonnea at night crawling on fallen logs and on low vegetation near a small fast-flowing stream. Bruce (1997) invariably found these salamanders close to the forest floor, either on the upper surfaces of broad-leaved herbaceous plants, on a pinnatifid fern, or on the vertical stem of a small plant. A single individual was observed crawling on leaf litter on the forest floor. The latter author remarked upon not being able to locate any salamanders during the

Received 17 November 2003.

Accepted 1 December 2003.

Distributed 19 December 2003 daytime, in spite of extensively raking leaf litter, and inspecting logs and arboreal bromeliads.

Long-term field studies by one of us (TL) on the herpetofauna of Rara Avis Rainforest Reserve, Heredia Province, Costa Rica $\left(84^{\circ} 02^{\prime} 50^{\prime \prime} \mathrm{W}, 10^{\circ} 17^{\prime} 00^{\prime \prime} \mathrm{N}, 550-700 \mathrm{~m}\right.$ elevation) led to the occasional discovery of adult $B$. colonnea in the leaf litter of premontane rainforest habitat during the daytime, or perched on top of the foliage of understory vegetation at night. The salamanders uncovered during the day were invariably curled up inside a dead leaf, often hanging upside-down. In order to investigate the daytime retreat preference of these salamanders a brief experiment was designed.

On the nights of March 7 and 8, 2002, two adult individuals of $B$. colonnea were encountered along a road cut through a section of secondary vegetation in Rara Avis, on the upper surfaces of broad-leaved plants (Melastomataceae), approximately $50 \mathrm{~cm}$ above the forest floor. Both salamanders were captured and subsequently released into an experimental arena during multiple observation periods while their behavior was being noted.

The experimental setup consisted of a $100 \times 100-\mathrm{cm}$ patch of secondary forest, representative of the original habitat of Bolitoglossa colonnea, surrounded by an area roughly $50 \mathrm{~cm}$ wide cleared of vegetation to 
prevent escape. Within this study plot, the salamanders had access to similar retreats and vegetation as in their natural habitat. During daylight hours, six separate 20-minute observation periods were carried out in which each salamander was placed on a broad leaf at a height of approximately $50 \mathrm{~cm}$ above the forest floor and its subsequent behavior recorded. Observations were repeated at night during two 3-hour periods between 20:00 and 23:00 h (Central Standard Time), after which the salamanders were released on the site of capture again. Total time in captivity for each individual salamander did not exceed 24 hours. Observations on Bolitoglossa colonnea during the behavioral experiments confirmed previous anecdotal field observations and revealed surprising additional natural history traits.

At night, individual $B$. colonnea had a salmon to tan dorsal coloration with very slight, dark mottling. Coloration of the ventral and lateral surfaces was of a lighter, cream hue (Figure 1A). By daytime, this color pattern had changed to a mottled ruddy to dark brown with scattered, irregularly shaped dark blotches. In addition to this conspicuous color change, the surface structure of the skin changed as well. The salamander's perfectly smooth integument at night, was roughened and marked with striking skin folds during the day. Apart from the characteristic transverse occipital ridge, the skin of B. colonnea displayed a series of short, raised longitudinal dermal folds during daylight hours (Figure 1B).

Throughout all observation periods, individual B. colonnea moved with very slow, deliberate movements in a stop-and-go fashion, often superimposing a rocking motion of the body on their forward movement. Locomotion occurred in the manner typical for bolitoglossine salamanders with only one foot off the substrate at any given time (Savage 2002). Movement by the observers triggered an immediate termination of any forward motion in the salamander. During times that wind moved the vegetation within the experimental setup, the salamander would immediately increase its walking speed to a continuous gait, resuming its stop-and-go tempo again as soon as the wind subsided.

Individual salamanders placed on an exposed section of vegetation during the daytime occasionally reacted with an explosive tail flip that propelled the entire animal off the vegetation. The salamander would scurry into the leaf litter and curl up inside a dead leaf.

Information in literature on $B$. colonnea mostly concerns morphological descriptions and brief notes on microhabitat or activity at the time of collecting, the main exception being the description of this species' reproductive cycle by Bruce (1997). In this publication, Bruce states that even his limited data illustrates how life history trends in neotropical plethodontids differ from those of North American species. Sudden flipping motions of the body and/or tail through rapid contraction of the trunk or tail musculature as a means of predator escape is known from other terrestrial salamanders but has not been reported yet for members of the genus Bolitoglossa. Savage (2002) mentions that body flipping is used by some bolitoglossine salamanders of the closely-related genus Oedipina as a means of defense against predators, especially if the disturbance is violent or if the salamander is touched. Individual $B$. colonnea observed during the current study did not display body or tail flip behavior when touched or picked up while on the ground. Similar observations were made by Taylor (1952) who noted the mild disposition of these salamanders and their lack of response upon capture. A more general anti-predator defense in Bolitoglossa appears to be to raise the tail, which is easily lost, and present it to a potential predator (e.g. Lee 2000, who reports this behavior for Bolitoglossa rufescens). Apart from the advantage of rapidly escaping a potentially hazardous situation, B. colonnea may use the body flip behavior when positioned on vegetation to return quickly to its daytime retreat in the leaf litter. If surface activity in $B$. 

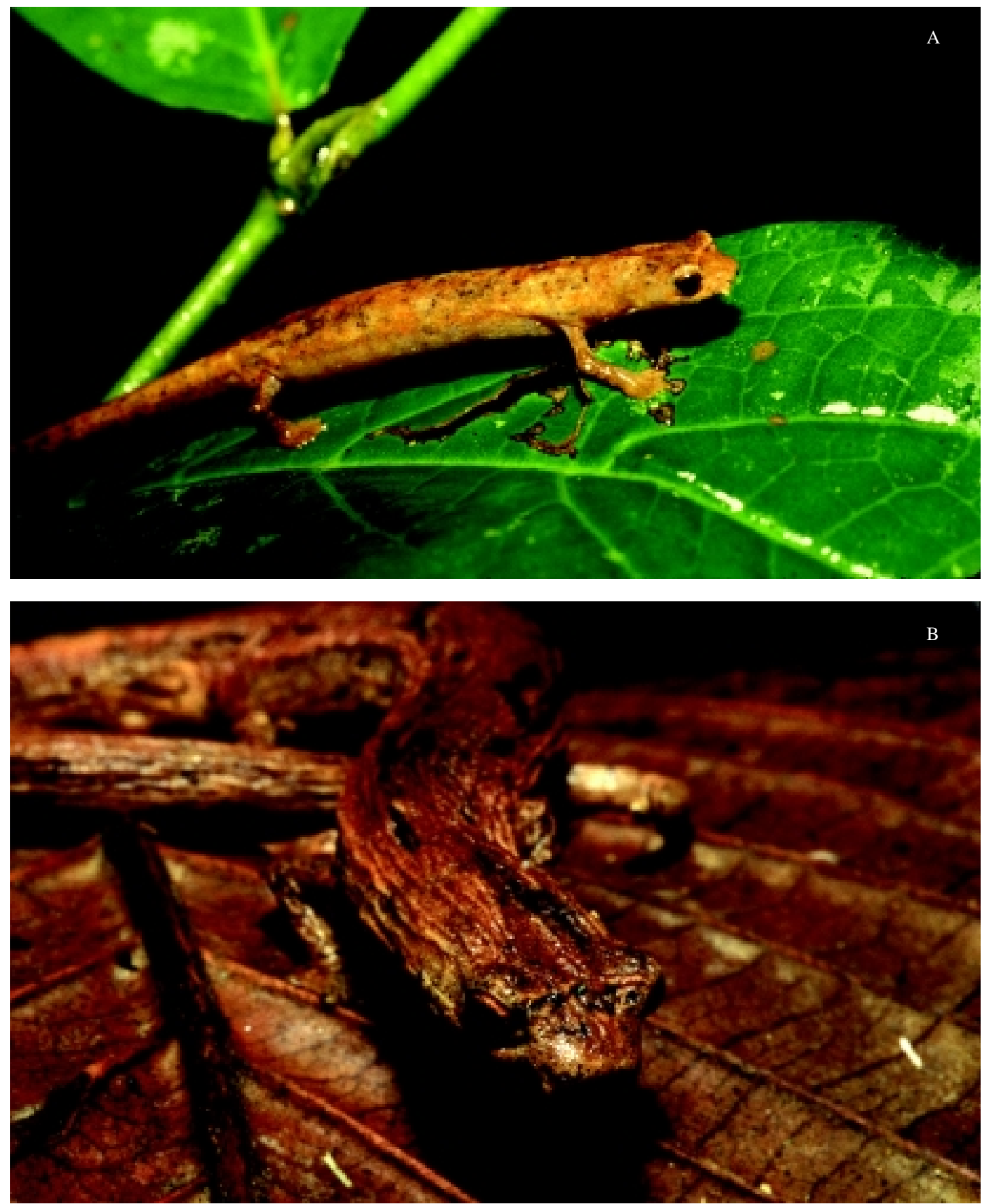

Figure 1 - The plethodontid salamander Bolitoglossa colonnea. (A) Night-time coloration (note the smooth skin); (B) $B$. colonnea during the day, showing the dark, mottled brown coloration and strongly ridged skin. Photographs (C) Twan Leenders. 
colonnea continues until daybreak, utilizing this technique in order to avoid prolonged exposure to daylight when climbing slowly down the vegetation, will effectively extend the salamander's surface activity period. Personal observations (by TL) indicate that these salamanders are actively moving around on the vegetation as late as 1:00 h (Central Standard Time), but information on the duration of nocturnal activity patterns in tropical bolitoglossines is lacking.

Previous field observations on Bolitoglossa colonnea and observations during this study seem to indicate that individuals of this species use curled, dead leaves for a daytime retreat. The salamander will tightly curl the tail around its body and adhere to the surface of the leaf, often in an upside-down position. B. colonnea appears to occur primarily in middle elevation rainforest habitat with a high annual precipitation and no pronounced dry season. Individual curled leaves frequently fill with water during downpours and may retain water for several days in closed-canopy rainforest habitat. The upside-down position that these salamanders assume inside the curled leaf possibly is a strategy to avoid exposure to rain water. The fact that these animals are hidden inside individual leaves may explain why Bruce (1997) was unable to uncover B. colonnea by raking the leaf litter in suitable habitat.

The combination of a mottled brown coloration and strongly ridged skin makes motionless $B$. colonnea look strikingly similar to a dead twig. Their slow, deliberate movements and the fact that individual $B$. colonnea remain motionless when potential threats are perceived all aid in resembling an inanimate object. The wind-induced change in locomotion pattern of these salamanders is another characteristic that adds to the camouflage of this salamander. Similar behavior has been noted for an assembly of neotropical vine snakes, which display a rocking motion superimposed on their forward movement, supposedly this oscillating motion serves to mimic a wind-blown twig (Nickerson et al. 1978). Similar movement patterns are seen in mantids and Old World chameleons. The daytime skin texture and coloration of $B$. colonnea appear to complement this behavior, improving its resemblance to a small branch.

\section{Acknowledgements}

We would like to thank Chris Freimuth and Sara Mooser and the Forman School Rainforest Project for their help with the observations. This study was carried out under permit numbers 027-ACCVC and resolution 190-96-OFAU issued by the Ministerio de Ambiente y Energía, Costa Rica.

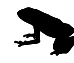

\section{References}

Bruce, R. C. 1997. Life history attributes of the salamander Bolitoglossa colonnea. Journal of Herpetology 31 : 592-594.

Dunn, E. R. 1926. The Salamanders of the Family Plethodontidae. Northampton, Massachusetts. Smith College Fiftieth Anniversary Publications. 441 pp.

Lee, J. C. 2000. A Field Guide to the Amphibians and Reptiles of the Maya World; the lowlands of Mexico, northern Guatemala, and Belize. Ithaca. Cornell University Press. 402 pp.

Nickerson, M. A., R. A. Sajdak and R. W. Henderson. 1978. Notes on the movements of some Neotropical snakes (Reptilia, Serpentes). Journal of Herpetology 12: 419-422.

Savage, J. M. 2002. The Amphibians and Reptiles of Costa Rica - a herpetofauna between two continents, between two seas. Chicago. University of Chicago Press. 934 pp.

Taylor, E. H. 1952. The salamanders and caecilians of Costa Rica. University of Kansas Science Bulletin 34: 695-791.

Wake, D. B. and J. F. Lynch. 1976. The distribution, ecology, and evolutionary history of plethodontid salamanders in tropical America. Natural History Museum of Los Angeles County, Science Bulletin 25: 1-65. 